\title{
Correspondence
}

\section{More support from mental health trusts needed to enable exposure to psychiatry for secondary school pupils}

The article by Kennedy \& Belgamwar ${ }^{1}$ nicely illustrates the importance of work experience in psychiatry for secondary school pupils. Unfortunately, this can be difficult to arrange in mental health trusts, despite recent guidance by the Royal College of Psychiatrists. ${ }^{2}$

Avon and Wiltshire Mental Health Partnership NHS Trust (AWP) Medical Education Department recently joined forces with Bristol University to provide a week-long summer school event for local sixth-formers. This programme included 2 days of work experience with consultant psychiatrists and their teams as well as half a day with local general practitioners. This followed extensive work by AWP to change their work experience policy to allow 17-year-olds to participate.

Our event consisted of taught sessions, similar to the programme detailed by Kennedy \& Belgamwar, to help the sixth-formers explore what it might be like to be a medical student and doctor, as well as a session entitled 'What is mental health?'. Our aim was to additionally support sixthformers in their application to medical school and so we also provided sessions for personal statement advice and interview practice. We held an evening social event with an opportunity for parents and guardians to attend a question and answer session while the pupils watched and discussed a film related to psychiatry. A summer school competition was held encouraging pupils to write a reflective piece on their experiences of the week, for which they produced some excellent and thoughtful pieces of work. All pupils were allocated a mentor, either a medical student or trainee in psychiatry, to provide support before, during and following the event.

Feedback from participants, parents and teachers has been very positive following our event, with pupils particularly valuing work experience, personal statement advice, interview practice sessions and being allocated a mentor. It was fantastic to hear them talking about their positive experiences of psychiatry during mock interview practice sessions. Encouragingly, 67\% of our participants said that they would consider a career in psychiatry ('strongly agree' or 'agree') following the event.

Kennedy \& Belgamwar's piece gives some excellent ideas for work experience programmes for secondary school pupils. I hope that more work experience and summer school programmes such as ours can be developed across the country, with the success and positive outcomes shown encouraging mental health trusts to lower their age limits for work experience to enable this.

1 Kennedy V, Belgamwar R. Impact of work experience placements on school students' attitude towards mental illness. Psychiatr Bull 2014; 38 159-63.

2 Mynors-Wallis L. College Position Statement: Work Experience in Psychiatry. Royal College of Psychiatrists, 2012. (https://www.rcpsych. ac.uk/pdf/Position\%20Statement\%20on\%20Work\%20Experience \%20in\%20Psychiatry.pdf).

Elizabeth Ewins, Clinical Teaching Fellow, Avon and Wiltshire Mental Health Partnership NHS Trust Medical Education Department, Bath, UK, email: elizabethewins@nhs.net

doi: 10.1192/pb.38.6.306

\section{Availability of work experience placements in psychiatry: the real picture}

We congratulate Kennedy \& Belgamwar ${ }^{1}$ for adding to the evidence base for the beneficial effects of work experience placements (WEPs) for secondary school pupils on stigma and recruitment, the two major problems facing psychiatry.

We searched the websites of all 54 mental health trusts (MHTs) in England and Wales for information regarding WEPs in clinical settings for 16- to 18-year-olds; only 11 mentioned WEPs. Of those, two confirmed that WEP was not available and one offered WEPs only in non-clinical areas. We then contacted all the $54 \mathrm{MHTs}$ under the Freedom of Information Act and inquired whether they offered WEPs in clinical settings to 16- to 18-year-olds. (The National Research Ethics Service confirmed that this study did not need ethical approval.) Twenty-five MHTs either did not respond to our inquiry or did not offer WEPs. Among the 29 MHTs that offer WEPs, 9 offer placements only in non-clinical areas. Responses of $12 \mathrm{MHTs}$ were ambiguous, for example they would offer WEPs on an ad hoc basis, on a limited basis, possibly not frontline, in low-risk areas, etc. Only $8 \mathrm{MHTs}$ offer WEPs in clinical areas for sixth-form pupils aged 16-18 years.

Our findings suggest that the WEPs in psychiatry, the key initiative to solve the twin problems of stigma and recruitment, are not working. Sixth-formers often struggle to get WEPs in psychiatry. Most MHTs websites often offer little or no information on WEPs. On the other hand, many mental health professionals state that they are keen to offer WEPs, but have no guidance. The few students who do manage to get WEPs in psychiatry do so because 'they know someone who knows someone'. Many consultants offer informal WEPs on their own initiative and at their own risk because their employer MHTs does not have the relevant policies.

We urge the College to develop a policy template for MHTs for WEPs for pupils, and to support MHTs to improve access to clinical WEPs, ensuring that information is readily available online.

1 Kennedy V, Belgamwar, RB. Impact of work experience placements on school students' attitude towards mental illness. Psychiatr Bull 2014; 38 : 159-63.

Ann Maria Albert, 4th-year medical student, University of Leeds, UK, email: um11ama@leeds.ac.uk; and Abdul Raoof, consultant psychiatrist and director of medical education, North Essex Partnership University NHS Foundation Trust, Chelmsford, honorary lecturer, Postgraduate Medical Institute, Anglia Ruskin University, Chelmsford. doi: $10.1192 / \mathrm{pb} .38 .6 .306 \mathrm{a}$

\section{Mainstream media today: the contemporary challenge in rebranding modern psychiatry}

While the issue of stigmatisation of psychiatry and psychiatrists is one that requires attention today, the demonisation of psychiatrists in fiction is an unashamedly historical piece. ${ }^{1}$ Novels and comics discussed by Hopson were published in 1868, 1923, 1946, 1951, 1952, 1954, 1962, 1964, 1965, 1971, 1976, 1988, 1995, 1996, 2001 and 2008. Many describe a bygone era for society and for psychiatry. In 